University of Nebraska - Lincoln

DigitalCommons@University of Nebraska - Lincoln

1999

\title{
Capillary Electrophoresis/Tandem Mass Spectrometry with Array Detection
}

\author{
L.J. Deterding \\ Laboratory of Structural Biology, National Institute of Environmental Health Sciences, North Carolina \\ K.B. Tomer \\ Laboratory of Structural Biology, National Institute of Environmental Health Sciences, North Carolina \\ J.M.Y. Wellemans \\ University of Nebraska - Lincoln \\ Ronald Cerny \\ University of Nebraska - Lincoln, rcerny1@unl.edu
}

M.L. Gross

University of Nebraska - Lincoln

Follow this and additional works at: https://digitalcommons.unl.edu/chemistrycerny

Part of the Chemistry Commons

Deterding, L.J.; Tomer, K.B.; Wellemans, J.M.Y.; Cerny, Ronald; and Gross, M.L., "Capillary Electrophoresis/ Tandem Mass Spectrometry with Array Detection" (1999). Ronald Cerny Publications. 8.

https://digitalcommons.unl.edu/chemistrycerny/8

This Article is brought to you for free and open access by the Published Research - Department of Chemistry at DigitalCommons@University of Nebraska - Lincoln. It has been accepted for inclusion in Ronald Cerny Publications by an authorized administrator of DigitalCommons@University of Nebraska - Lincoln. 


\title{
Capillary electrophoresis/tandem mass spectrometry with array detection
}

\author{
L.J. Deterding' and K.B. Tomer \\ Laboratory of Structural Biology, National Institute of Environmental Health Sciences, PO Box 12233, Rescarch Triangle Park, \\ NC. 27709, USA.
}

J.M.Y. Wellemans ${ }^{a}$, R.L. Cerny and M.L. Gross ${ }^{b}$

Department of Chemistry, University of Nebraska-Lincoln, Lincoln, NE 68588, USA.

\begin{abstract}
Mixtures of standard compounds of biological interest were analyzed by capillary electrophoresis in conjunction with tandem foursector mass spectrometry (MS/MS) using an array detector. Capillary electrophoresis offers extremely high separation efficiencies while array detection allows for the simultaneous acquisition of a large fraction of a tandem mass spectrum and high utilization of the sample ions produced. Consequently, improvements in sensitivity and structural information were observed for the combined techniques in comparison to similar measurements with a four-sector and a single-point detector. Coaxial continuous-flow fast atom bombardment was used to create $(M+H)$ ' precursor ions of the separated analytes and their product ion spectra were acquired from femtomole levels in electrophoretic real-time. The limit-of-detection for the acquisition of MS/MS data from electrophoreticallyseparated peptides was 35-100 fmol. The MS/MS data acquired at these levels showed cleavages of the peptide backbone (i.e. to give a and $y$ ions) and production of immonium ions from the constituent amino acids. Acquisition of the spectra via the array detector is more routine and, at the 100 femtomole level, provides more structurally informative ions and yields better ion statistics than comparable spectra acquired with a point detector.
\end{abstract}

Keywords: Capillary electrophoresis, tandem mass spectrometry, array detection, coaxial continuous flow FAB, peptides.

\section{Introduction}

Mass spectrometry is a powerful technique for the analysis of biological samples and complex mixtures. Burlingame et $a l$.' recently reviewed the developments and influence of mass spectrometry in this area. Some of the most challenging problems in biological research require the determination of low concentrations of analytes or of complex mixtures in small volumes. As these needs exist, much

\footnotetext{
'Corresponding author: Leesa.J. Deterding, National Institute of Environmental Health Sciences, PO Box 12233 MD FO-03, Research Triangle Park, NC 27709, USA; phone: +1-919-541-3009; fax: +1-919-5410220; e-mail: deterding(niehs.nih.gov.

"Present address: Deparment of Bioanalyical Services, Microbiological Associates, Rockville, MD 20850, USA.

"Present address: Department of Chemistry, Washington University, CB 1134, St Louis, MO 63130, USA.
}

effort has been applied to the development of methods and/or techniques to enhance mass spectrometric sensitivity.

One recent development is the use of microelectrospray ionization ${ }^{2}$ in which a fused-silica needle is packed with $1 \mathrm{~cm}$ of a reversed-phase liquid chromatography (LC) packing. The packing acts as a desalting/preconcentration device prior to electrospray ionization. In addition, nanospray ionization sources, ${ }^{3,4}$ which utilize nanoliter per minute flow rates, were developed to provide more efficient ionization. In either case, these sources allowed mass spectrometric analysis of small volumes of samples.

Tandem mass spectrometry (MS/MS) is the technique of choice to gain as much structural information as possible about a compound of interest. The compatibility of the new ionization sources with the acquisition of tandem mass spectra, therefore, is also of interest. The amount of material reported for the acquisition of a product-ion spectrum of a peptide was $50 \mathrm{fmol}$ with a micro-electrospray source ${ }^{2}$ and 25 fmol with a nanospray source., 
An alternative approach for enhancing the sensitivity of the analysis of complex biological samples is the combination of capillary electrophoresis (CE) with mass spectrometry using an array detector. Recent developments in CE/MS have greatly increased the ability to analyze and characterize biological samples. Zone electrophoresis was first described by Mikkers et $a l^{5}$ and further characterized in 1981 by Jorgenson and Lukacs. ${ }^{6}$ It has the capability to resolve more than $1 \times 10^{6}$ theoretical plates in a 20 -minute electropherogram; this is the highest resolution achievable for any separation technology. ${ }^{6 \%}$ CE separation efficiencies are orders of magnitude higher than those for conventional LC.

Because mass spectrometry is a nearly universal detector, it is a desirable detection system for capillary electrophoresis. ${ }^{9}$ Capillary electrophoresis was first coupled with a quadrupole mass spectrometer in 1987, using electrospray ionization. ${ }^{10}$ The entire column effluent of $50: 50$ methanol : $10^{4} \mathrm{M} \mathrm{KCl}$ was introduced into the mass spectrometer, and no make-up flow was employed. Shortly after this report appeared, our laboratory at the National Institute of Environmental Health Sciences (NICHS) reported the coupling of capillary electrophoresis with a coaxial continuous-flow fast-atom bombardment (CF-FAB) ion source on a magnetic sector instrument. ${ }^{11,12}$ This design incorporated a coaxial arrangement of two fused-silica capillaries. The FAB matrix is introduced as a sheath flow that is separate from the CE flow, thus allowing independent optimization of the matrix composition and the CE separation system. High separation efficiencies have been obtained by using $C E$ in conjunction with coaxial CF-FAB on low femtomole levels of peptides when full-scan mass spectra were obtained.'

In addition, we have obtained product-ion spectra in electrophoretic real-time from 100-500 fmol of peptides. ${ }^{11,12}$ A major limitation of that approach is that the tandem mass (MS/MS) spectra were obtained by scanning over a singlepoint detector. For $\mathrm{CE} / \mathrm{MS} / \mathrm{MS}$ acquisitions, it is possible that there may not be sufficient time to acquire reliable spectra. A corollary to the high separation efficiencies associated with $C E$ is extremely narrow peak widths. A typical CE peak may be three to five seconds wide at half-height. It may not always be possible, therefore, to obtain a representative product-ion spectrum from a scanning magnetic-sector instrument in that short period of time. For instruments capable of simultaneous detection, however, the narrow peaks characteristic of CE may be advantageous since the sample is present in a very narrow, concentrated band. The production of an instantaneous high ion current may result, thus increasing the sensitivity of the method.

To investigate this possibility for the analysis of biological samples, we recently adapted the coaxial CF-FAB interface to a VG ZAB-T four-sector mass spectrometer ${ }^{13}$ equipped with a $15 \mathrm{~cm}$ channel electron multiplier array detector. The design of this instrument allows for the simultaneous acquisition of a large percentage of the ions in the tandem mass spectrum and thus a high utilization of the sample ions produced. In this study, peptide mixtures were sepa- rated by capillary electrophoresis, and product-ion spectra were acquired as the peptides exited the CE column. In addition, the limit-of-detection (LOD) of this system for the MS/MS analysis of electrophoretically-separated analytes was determined.

The purpose of this article is to report the capability of a tandem four-sector mass spectrometer for the determination of peptides. We recognize that the emphasis in mass spectrometry has shifted from tandem sector instruments in favor of simpler, lower-cost, smaller instruments, for example, ion traps, triple quadrupoles, quadrupole/time-of-flight combinations, that have high sensitivities and are more compatible with electrospray ionization (ESI) than are high-voltage sector instruments. Nevertheless, tandem sectors once held a preeminent role in peptide mass spectrometry and they remain one of the few ways to achieve high-energy collisional activation of ions. Therefore, reports of the capabilities of four-sector instruments provide a useful reference point for the past and for the future evolution of mass spectrometric instrumentation.

\section{Experimental}

\section{Chemicals}

The peptides and the glycerol were purchased from Sigma Chemical Co. (St Louis, MO, USA) and were used as delivered. Ammonium acetate was obtained from Mallinckrodt, Inc. (Paris, KY, USA). Glacial acetic acid and ammonium hydroxide were purchased from Fisher Scientific (Fair Lawn, NJ, USA) and the heptafluorobutyric acid was obtained from Pierce (Rockford, IL, USA). All solutions were prepared using $18 \mathrm{M} \Omega$ water (Hydro Service and Supplies, Research Triangle Park, NC, USA).

\section{Capillary electrophoresis}

An Isco capillary electrophoresis system (Isco, Inc., Lincoln, NE, USA) with a reversible power supply was modified for use with the mass spectrometer. A hole was drilled in the side of the Plexiglas cover of the CE system in order to extend the CE capillary from the CE system into the inlet probe of the mass spectrometer. Either a bare fused-silica capillary or a derivatized fused-silica capillary with the dimensions of $15 \mu \mathrm{m}$ id $\times 150 \mu \mathrm{m}$ od $\times 1 \mathrm{~m}$ was used. The derivatized fused-silica capillary was silylated with (3aminopropyl)trimethoxysilane (APS). ${ }^{12}$ Prior to use, the capillaries were flushed with buffer solution for approximately $1 \mathrm{~h}$. The buffers used in this work were either $5 \mathrm{mM}$ ammonium acetate or $10 \mathrm{mM}$ acetic acid, with $\mathrm{pH}$ adjustments made with ammonium hydroxide. All buffers were filtered through a $0.2 \mu \mathrm{m}$ filter and were degassed immediately prior to use.

Sample introduction was by means of a pressurized injection vessel that has been described previously. ${ }^{14,15}$ For the injection of a specific amount of an analyte, a microvial or an Eppendorf tube containing the analyte solution was 
placed in the injection vessel. A pressure of helium was applied for a specific period of time to inject a measured volume of the sample solution onto the column. The column was removed from the pressure vessel and placed in the CE buffer solution together with the CE electrode. Once the CE voltage was applied, migration of the analytes through the column commenced. A potential drop of either $+22 \mathrm{kV}$ for the bare fused-silica CE column, or $-30 \mathrm{kV}$ for the APS CE capillary, was maintained across the 1 meter length during the analyses.

\section{Coaxial continuous-flow $F A B$}

A standard VG continuous-flow FAB source heated to $40^{\circ} \mathrm{C}$ was used in these studies. The coaxial continuous-flow FAB probe was custom fabricated and has been described previously. ${ }^{11,12,16}$ Briefly, a coaxial arrangement of fusedsilica capillaries was used to deliver the FAB matrix and the $\mathrm{CE}$ effluent to the probe tip. The analytes were separated in the inner fused-silica capillary $(15 \mu \mathrm{m}$ id $\times 150 \mu \mathrm{m}$ od $)$ while the matrix from a microliter syringe pump (Isco, lnc., Lincoln, NE, USA) flowed through the sheath column $(160 \mu \mathrm{m}$ id $\times 360 \mu \mathrm{mod})$. The matrix flow rate was $0.3 \mathrm{~mL} \mathrm{~min}{ }^{\prime}$ and its composition was $25 \%$ glycerol in water. Heptafluorobutyric acid $(5 \mathrm{mM})$ was added to ensure electrical contact between the CE capillary and the probe tip.

\section{Mass spectrometer}

All data were acquired on a VG ZAB-T four-sector mass spectrometer (VG Analytical, Altrincham, UK) that was previously described. ${ }^{13}$ The instrument consists of a ZAB-SE as the first stage (MS-1) which was operated at $8 \mathrm{kV}$. A cesium gun operated at $30 \mathrm{kV}$ was used to desorb the ions. FAB mass spectra were acquired by using $2.5-7 \mathrm{~s}$ decade 'scans. The second-stage mass spectrometer is of a reversed-geometry Mattauch-Herzog type design. At an acceleration voltage of $8 \mathrm{kV}$, the magnetic sector had an upper mass limit of $m / z 15,000$. The second electric sector employs an inhomogeneous electric field established by applying appropriate voltages to a series of shim electrodes. The ion beam travels between the electrode pairs and is double-focused onto a $15 \mathrm{~cm}$ array detector. The collision cell was floated at $2 \mathrm{kV}$. Helium or argon was used as the collision gas and the main ion beam was attenuated to $70 \%$ of its original value by admitting an appropriate amount of the gas to the collision cell. The array exposure times were $1 \mathrm{~s}$. Data analysis was accomplished with the commercial OPUS data system supplied by the manufacturer.

\section{Results and discussion}

\section{CE/MS acquisitions}

The first experiments were carried out to evaluate the capability to acquire mass spectra of mixture components. The first example is the separation of a solution of eight synthetic peptides, Met-Leu-Phe (MLF) $\left[(\mathrm{M}+\mathrm{H})^{+}=410\right]$, morphiceptin $\left[(\mathrm{M}+\mathrm{H})^{+}=522\right], \beta$-casomorphin $\left[(\mathrm{M}+\mathrm{H})^{+}\right.$ $=790]$, leucine-enkephalin $\left[(\mathrm{M}+\mathrm{H})^{+}=556\right]$, leucineenkephalinamide $\left[(\mathrm{M}+\mathrm{H})^{+}=555\right]$, methionine-enkephalin $\left[(\mathrm{M}+\mathrm{H})^{+}=574\right]$, Phe-Leu-Glu-Glu-lle (FLEEI) $\left[(\mathrm{M}+\mathrm{H})^{+}\right.$ $=650]$ and proctolin $\left[(\mathrm{M}+\mathrm{H})^{+}=649\right]$, using an untreated fused-silica CE capillary and a coaxial CF-FAB interface with mass spectrometric detection. The CE buffer employed to obtain this separation was $5 \mathrm{mM}$ ammonium acetate, $\mathrm{pH}$ 8.5. FAB mass spectra of the analytes were acquired as each peptide migrated off the CE capillary. The magnet of MS- 1 was scanned from $m / z 835$ to 350 at $2.5 \mathrm{~s}$ decade '. A timed injection of $2 \mathrm{~s}$ at 250 psi was used to introduce the analytes in amounts ranging from $79 \mathrm{fmol}$ for $\beta$ casomorphin to $153 \mathrm{fmol}$ for MLF. The single-ion electropherograms of the $(\mathrm{M}+\mathrm{H})^{+}$ion of each of the eight peptides are shown in Figure 1. In the single-ion mass electropherogram of FLEEI, there is a relatively low-intensity peak with a migration time of $15 \mathrm{~min} 30 \mathrm{~s}$ prior to the higher intensity peak at $18 \mathrm{~min} 40 \mathrm{~s}$. This small peak is due to the

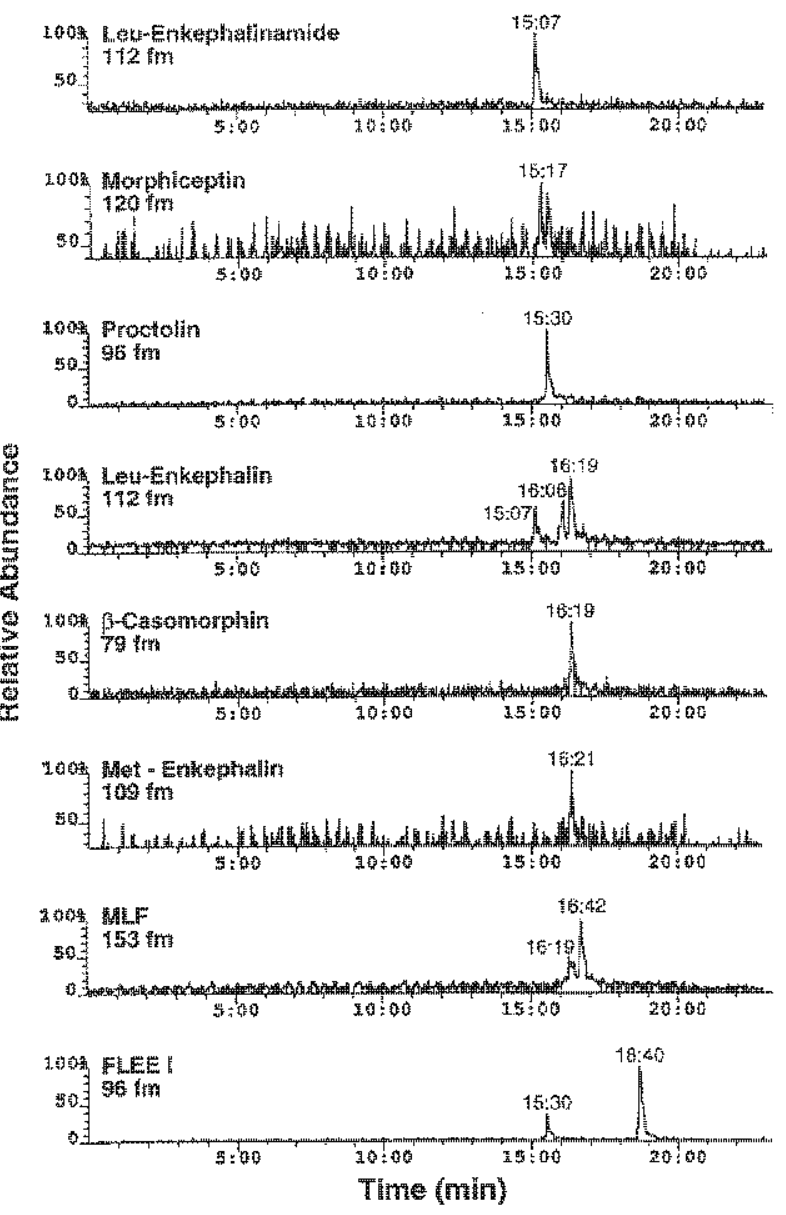

Figure 1. Single-ion electropherograms of the protonated molecules from a mixture of peptides. Numbers associated with the peaks are migration times. CE conditions: $5 \mathrm{mM}$ ammonium acetate, $\mathrm{pH}=\mathbf{8 . 5}$. 
${ }^{13} \mathrm{C}$-isotopomer of protonated proctolin. Likewise, in the electropherogram of protonated leucine-enkephalin, the small peak at a migration time of $15 \mathrm{~min} 7 \mathrm{~s}$ is due to the ${ }^{13} \mathrm{C}$ isotopomer of leucine-enkephalinamide.

There are additional peaks observed in the electropherograms of the $(\mathrm{M}+\mathrm{H})^{+}$ions of MLF and leucineenkephalin; these components co-migrate with $\beta$ casomorphin at a migration time of $16 \mathrm{~min} 19 \mathrm{~s}$. We postulate that these peaks are due to complex formation, either aggregates or micelles. Because some of these peptides are hydrophobic in nature, it is possible that these peptides form micelles at the concentrations employed. The analyte concentrations in the mixture were $13-25 \mathrm{mM}$. For example, the concentration of $\beta$-casomorphin in the $\beta$-casomorphin band may be sufficient to form micelles that can carry MLF and leucine-enkephalin along in the $\beta$-casomorphin band.

Zone broadening, due to the adsorption of positively charged peptides onto the CE capillary wall, is significantly reduced when fused-silica capillaries are used in which the surface silanol groups have been modified with aminopropyl groups. ${ }^{12}$ For the CE analysis of angiotensin-related peptides, therefore, such an APS capillary with a CE buffer of $10 \mathrm{mM}$ acetic acid (pH 3.5) was used. The single-ion electropherograms of the $(\mathrm{M}+\mathrm{H})^{+}$ion from the separation of $80 \mathrm{fmol}$ of angiotensin $\mathrm{l}\left[(\mathrm{M}+\mathrm{H})^{+}=1296.7\right], 100 \mathrm{fmol}$ of angiotensin $\mathrm{ll}\left[(\mathrm{M}+\mathrm{H})^{+}=1046.5\right], 80 \mathrm{fmol}$ of [val $\left.{ }^{5}\right]$-angiotensin $\mathbf{l}\left[(\mathrm{M}+\mathrm{H})^{+}=1282.7\right]$ and $100 \mathrm{fmol}$ of [ $\left.\mathrm{val}^{5}\right]$-angiotensin $\left.\mathrm{ll}(\mathrm{M}+\mathrm{H})^{+}=1032.5\right]$ is shown in Figure 2. The mass spectrometer was scanned from $m / z \quad 1350$ to 990 at $7 \mathrm{~s}$ decade '. Because these peptides have the same pl value $(\mathrm{pl}=7)$, the separation of these four compounds is extremely difficult to achieve by CE. The angiotensin $\mathrm{Il}$ and $\left[\mathrm{val}^{5}\right]$-angiotensin $\mathrm{ll}$ co-migrate, while the [val $\left.{ }^{5}\right]$-angiotensin $\mathbf{I}$ and angiotensin $\mathbf{I}$ also co-migrate. Very good signal-tonoise ratios $(\mathrm{S} / \mathrm{N}>10: 1)$ were obtained for the $(\mathrm{M}+\mathrm{H})^{+}$ signals for all the angiotensin components of the mixture at these femtomole levels. The levels of analytes observed in these $\mathrm{CE} / \mathrm{MS}$ analyses are comparable to those observed using a ZAB-4F mass spectrometer, ${ }^{11,12}$ which is to be expected given that only the first stage of the instrument was used.

\section{CE/MS/MS with array detection}

The primary goal of this project was to evaluate combined capillary electrophoresis and tandem mass spectrometry with array detection for the acquisition of product-ion spectra for structural elucidation. A specific aim was to improve the sensitivity that can be obtained with tandem sector MS. We, therefore, investigated the capability and the detection limits for these combined techniques by using the same peptide mixtures that were employed in the CE/MS experiments and which contained some of the same analytes that were used in the original work. ${ }^{11,12}$ Because the peaks are narrow (for example, 3-5 s wide at half-height) and the analysis times are rapid (typically $10 \mathrm{~min}$ or less) with capillary electrophoresis, it is difficult to change the mass spectrome-

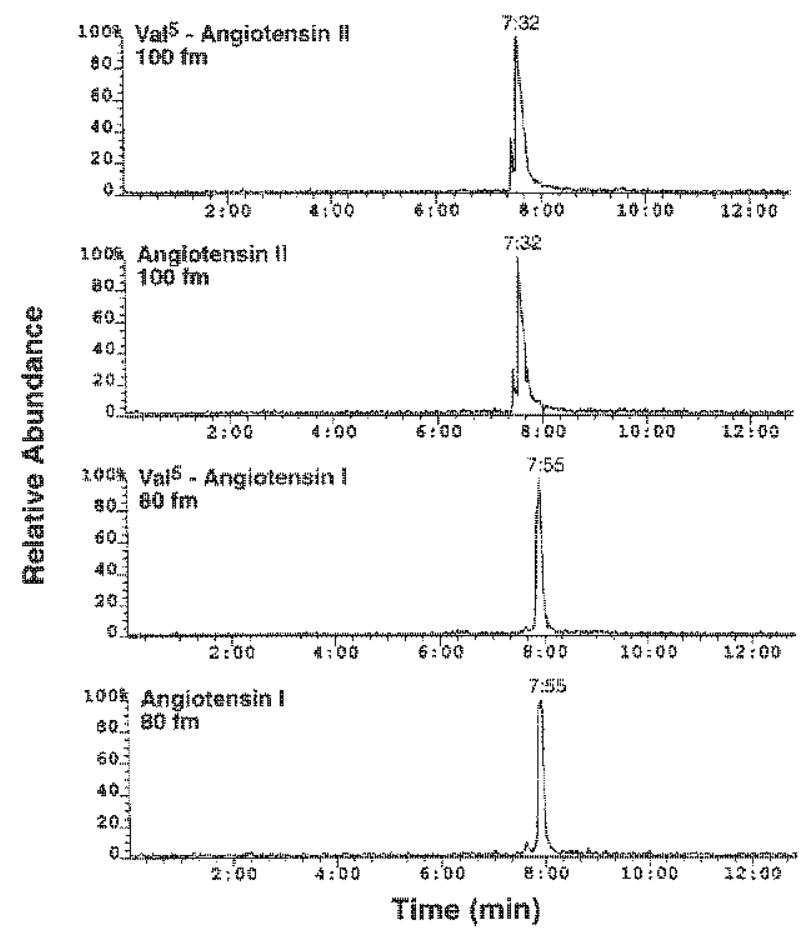

Figure 2. Single-ion electropherograms of the protonated molecules of a mixture of angiotensin-related peptides. Numbers associated with the peaks are migration times. CE conditions: $10 \mathrm{mM}$ acetic acid, $\mathrm{pH}=\mathbf{3 . 5}$.

ter focussing to various $(\mathrm{M}+\mathrm{H})^{+}$ions to allow the acquisition of more than one collisional-activation decomposition (CAD) spectrum per sample injection. For the analysis of the mixture of eight peptides, we injected the mixture for $\mathrm{CE}$ separation eight times so that the product-ion spectrum of each analyte was acquired as it migrated from the CE capillary. Representative spectra of four of the eight compounds were selected to be shown in Figure 3 . The product-ion spectrum of $470 \mathrm{fmol}$ of the $(\mathrm{M}+\mathrm{H})^{+}$ion of FLEEl shows clearly the loss of water from the protonated molecular ion and the b- and $\mathbf{y}$-series ions resulting from backbone cleavages [see Figure 3(a)]. Nomenclature for the peptide cleavages is that of Roepstorff ${ }^{17}$ as modified by Biemann. ${ }^{18}$ The $\mathbf{a}-, \mathbf{z}$ - and $\mathbf{x}-$ series cleavage ions are produced at relatively lower abundances than are the $\mathbf{b}$ - and $\mathbf{y}$-series ions.

The product-ion spectra of protonated $\beta$-casomorphin, leucine-enkephalin and MLF [see Figure 3(b-d)] were obtained for injections of 390,280 and $230 \mathrm{fmol}$, respectively. Structurally-informative ions are produced by cleavages of the peptide backbone. When analyzing these low levels of material, however, interference from the glycerol matrix can occur. For example, the losses of one, two, three and even four glycerols from a matrix ion that was coselected with the peptide $(\mathrm{M}+\mathrm{H})^{+}$are observed [Figure $3(\mathrm{~b})]$. 

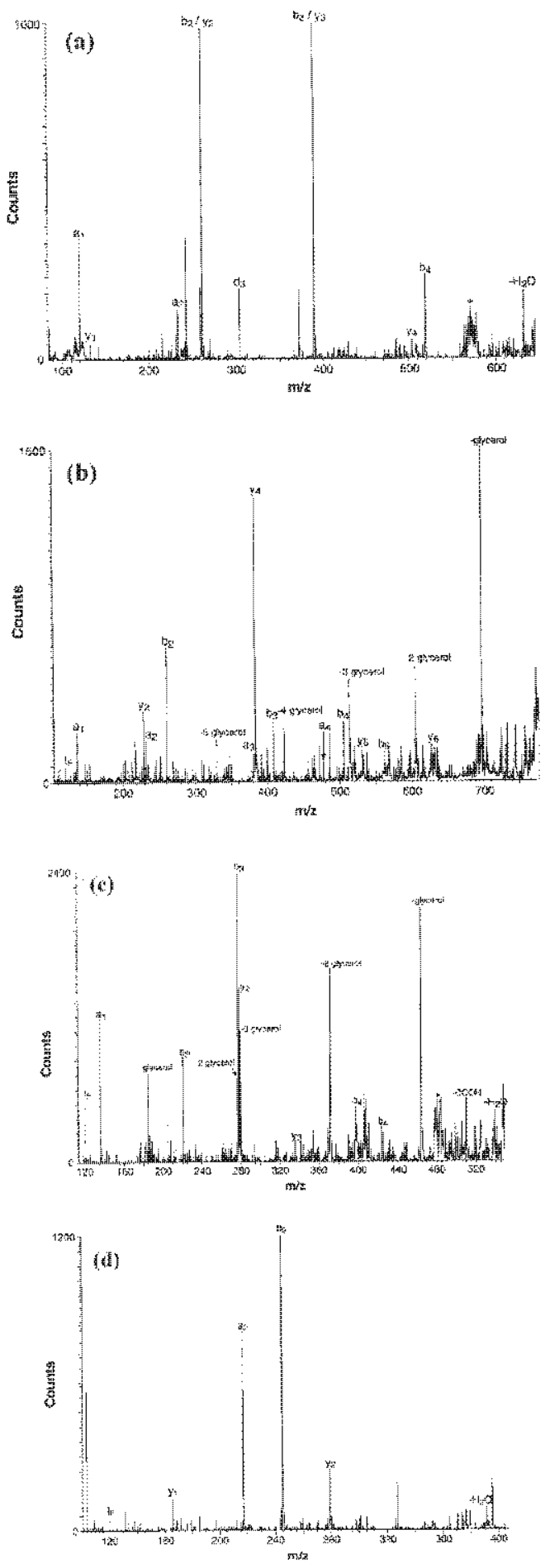

Figure 3. CE/MS/MS of the protonated molecules of the peptides whose separation is shown in Figure 1. The insets show product-ion spectra of (a) $470 \mathrm{fmol}$ of FLEEI; (b) $390 \mathrm{fmol}$ of $\beta$ casomorphin; (c) $280 \mathrm{fmol}$ of leucine-enkephalin and (d) $230 \mathrm{fmol}$ of MLF. Peaks labeled with an asterisk ( $\left(^{*}\right)$ may be due to metastable decompositions occurring after the second magnet sector [e.g. products from losses of $\mathrm{C}_{4} \mathrm{H}_{8}$ from a leucine side chain in FLEEI (a) or leu enkephalin (c) may give the designated peaks in (a) and (c)]. CE conditions as those reported for Figure 1.
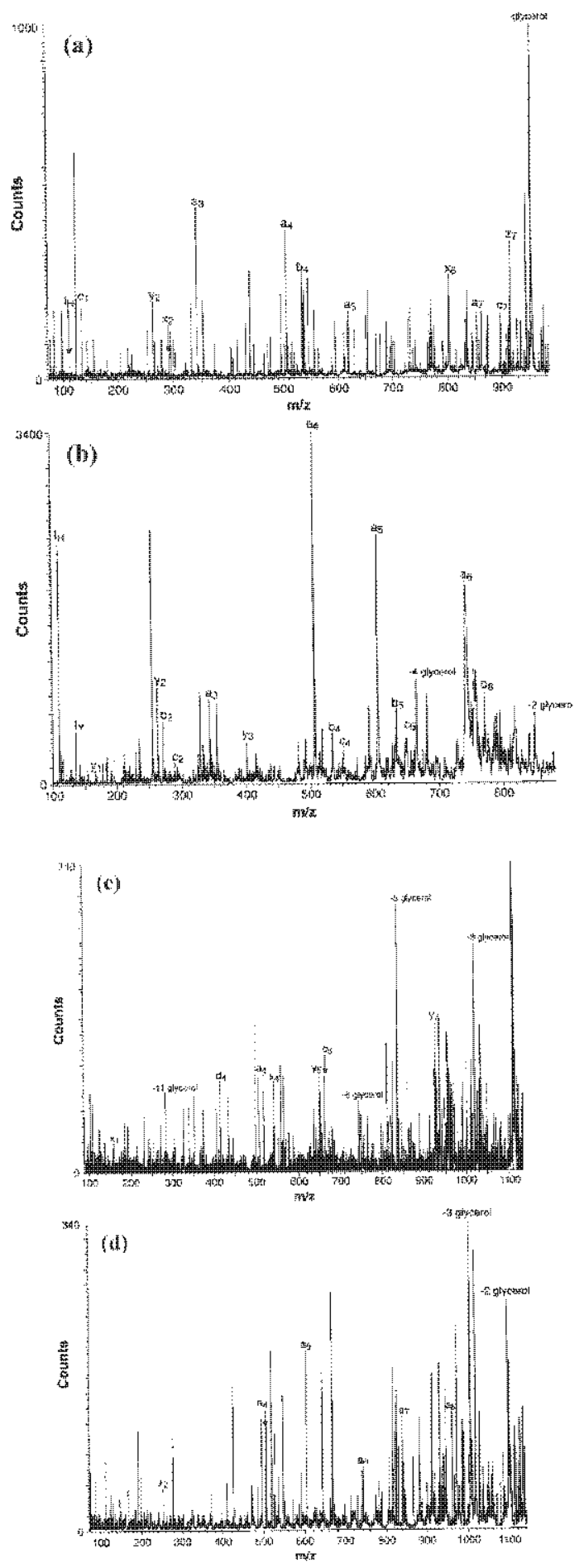

Figure 4. CE/MS/MS of the protonated molecules of the angiotensin-related compounds whose separation is shown in Figure 2. The insets show product-ion spectra of (a) $180 \mathrm{fmol}$ of angiotensin $\mathrm{II} ;$ (b) $360 \mathrm{fmol}$ of [val $\left.{ }^{5}\right]$-angiotensin $\mathrm{II}_{;}$(c) $500 \mathrm{fmol}$ of angiotensin I; and (d) $360 \mathrm{fmol}$ of [val ${ }^{5}$-angioten$\sin$ I. CE conditions are those reported for Figure 2. 
For the acquisitions of product-ion mass spectra of the angiotensin-related compounds, the CE analyses were repeated four times. Product-ion mass spectra were acquired for each analyte $(180-500 \mathrm{fmol})$ as they emerged from the CE capillary. The product-ion, collisional-activation decomposition (CAD) spectra for the $(\mathrm{M}+\mathrm{H})^{+}$ions of angiotensin $\mathbf{I l},\left[\mathrm{val}^{5}\right]$-angiotensin $\mathbf{l l}$, angiotensin $\mathbf{I}$ and $\left[\mathrm{val}^{5}\right]$-angiotensin I [Figures 4 (a-d), respectively) clearly show fragment ions resulting from fragmentation of the peptide backbone. lons characteristic of high collision energies (for example, $\mathbf{d}$ ions) are also observed. ${ }^{18}$ As for the product-ion spectra in Figure 3 , ions due to the loss of glycerol molecules are observed, indicating co-selection of matrix and peptide ions. Although some of the spectra have low $\mathrm{S} / \mathrm{N}$ (background) ratios, structurally-informative ions are observed. In Figure 4(b), complete series of $\mathbf{a}$ and $\mathbf{b}$ ions, except for $\mathbf{a}_{1}, \mathbf{a}_{2}, \mathbf{b}_{1}, \mathbf{b}_{3}$ and $\mathbf{b}_{7}$, are obtained, allowing for a nearly complete sequence determination of the peptide.

The amounts of peptides used for the acquisition of CAD spectra with an array detector from electrophoretically-separated analytes are comparable to those levels previously reported when using a $\mathrm{ZAB}-4 \mathrm{~F}$ instrument equipped with a point detector.' ${ }^{12}$ It should be noted, however, that acquisition of the spectra using the array detector is more routine at these levels. An advantage of the array detector is that simultaneous detection of a large percentage of the tandem mass spectrum should allow for an improvement in the limit-of-detection (LOD). To determine the LOD for the acquisition of product-ion spectra in electrophoretic real-time by using the array detector, several experiments were performed and are described in the following section.

\section{CE/MS/MS limit-of-detection}

Back-to-back injections of peptide mixtures were used to determine the limit-of-detection for the acquisition of real-time product-ion spectra when using the array detector. For the mixture of eight synthetic peptides, the LOD was determined for MLF so that a direct comparison could be made with the LOD determined on a four-sector instrument equipped with a single-point detector. " One of the angiotensin peptides was also chosen for LOD determination. For each injection, the product-ion spectrum of either MLF or $\left[\mathrm{val}^{5}\right]$-angiotensin l was acquired following separation of the peptide mixture in the CE capillary. The LOD for the tandem mass spectrometric determination of the tripeptide MLF is approximately $75 \mathrm{fmol}$ acquired from an injection of a $2.4 \times 10^{6} \mathrm{M}$ solution and is established by the CAD spectrum in Figure 5(a). lons resulting from the matrix background were subtracted. Subtraction is relatively easy to accomplish because a spectrum of matrix ions is acquired immediately before or after emergence of the analyte. Most of the major ions in the spectrum are identifiable at an $\mathrm{S} / \mathrm{N}>\mathbf{3}$ as backbone cleavages (i.e. $\mathbf{y}_{1}, \mathbf{a}_{2}, \mathbf{b}_{2}$ and $\mathbf{y}_{2}$ ). In addition, the immonium ions from the amino acids methionine and leucine are also observed. The fragment ions observed in this product-ion spectrum are nearly identical to those
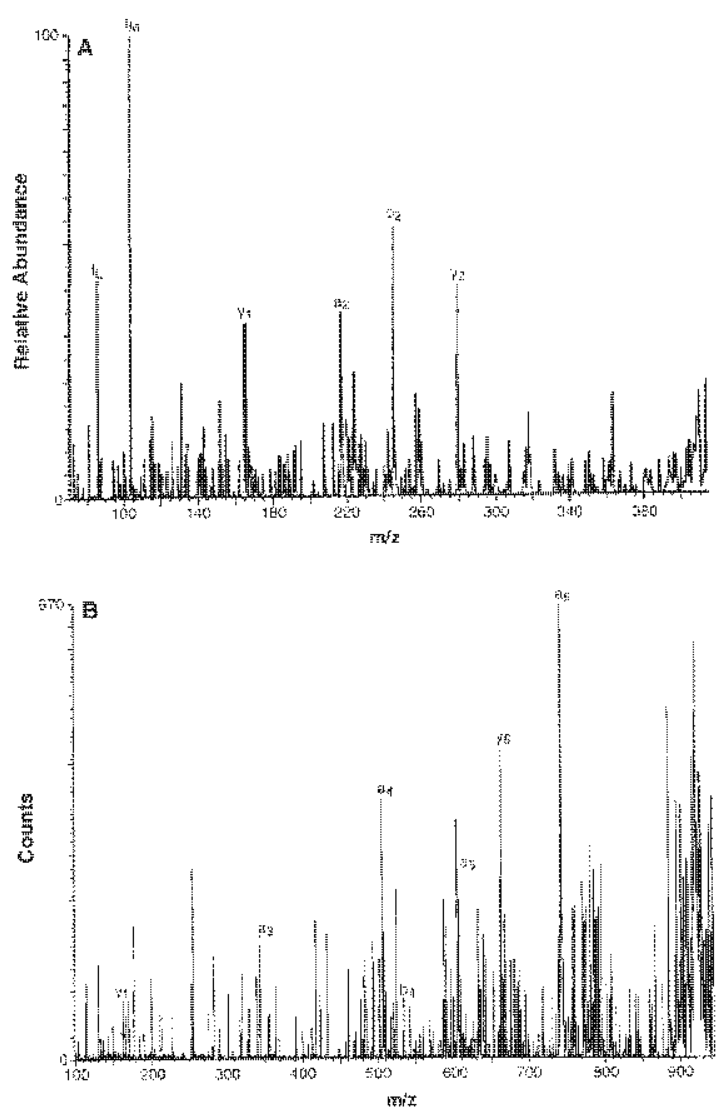

Figure 5. CE/MS/MS of the protonated molecules of (a) $75 \mathrm{fmol}$ of MLF and (b) $90 \mathrm{fmol}$ of [val $\left.{ }^{5}\right]$-angiotensin II. Spectra were obtained by subtraction of the matrix spectrum from the experimental spectrum.

observed in the tandem spectrum acquired from $230 \mathrm{fmol}$ of MLF [Figure 3(d)]. By comparison with the CE/MS/MS experiment with MLF using a point detector, "improved ion statistics are observed by using the array detector. The product-ion spectrum of $130 \mathrm{fmol}$ of MLF obtained with the point detector is skewed due to the short scan time necessary to acquire the spectrum with the point detector. In addition, more structurally informative sequence ions are observed using the array detector. With the point detector, the only ions from peptide backbone cleavages observed were the $\mathbf{a}_{2}$, $b_{2}$ and $y_{2}$ ions."

The product-ion spectrum of [ $\left.\mathrm{val}^{5}\right]$-angiotensin $\mathbf{l}$ shown in Figure 5(b) establishes an LOD of approximately $90 \mathrm{fmol}$ for this peptide. The product ions that are formed are $\mathbf{a}$ and $\mathbf{y}$ types; the a-series is nearly complete $\left(\mathbf{a}_{3}, \mathbf{a}_{4}, \mathbf{a}_{5}\right.$ and $\mathbf{a}_{6}$ are all observed). Many interference ions are in the product-ion spectrum because, for this amount of sample, the matrix ions that are co-selected are of comparable levels to or may exceed the levels of the analytes.

The LOD achievable by using this system, therefore, for the MS/MS determination of an analyte separated by CE is in the range of $100 \mathrm{fmol}$. At this level, one would have diffi- 
culty sequencing a totally unknown peptide, but a peptide sequence could be verified. These levels are similar to those reported for $\mathrm{C} \mathrm{E} / \mathrm{MS} / \mathrm{MS}$ acquisitions of peptides introduced by electrospray ionization. ${ }^{19} 22$ In addition, similar results were obtained for the MS/MS of peptides introduced using either micro-electrospray ${ }^{2}$ or nanospray. ${ }^{3,4}$ The use of an ionization technique that generates less chemical background (for example, electrospray or nanospray) than does FAB may improve the LODs obtainable on this instrument. In addition, various on-line sample pre-enrichment approaches, such as membrane preconcentration ${ }^{23}$ and solid-phase microextraction, ${ }^{26}{ }^{29}$ for use with CE have demonstrated the ability to enhance MS sensitivities.

\section{Conclusions}

Capillary electrophoresis was successfully coupled with a tandem mass spectrometer equipped with an array detector. Because CE offers extremely high resolving power and mass spectrometric detection provides high structural information and high sensitivity, the combination of these two techniques provides a powerful tool for the analysis of complex mixtures. The use of array detection allows product-ion mass spectra to be recorded at $\sim 100 \mathrm{fmol}$ level from electrophoretically-separated analytes. Although the levels obtained here are comparable with the LOD values obtained using the ZAB-4F mass spectrometer with a single-point detector," the data acquired with the array detector provide better ion statistics and more structurally informative fragment ions. The use of nanospray ionization or sample preconcentration in combination with capillary electrophoresis on a mass spectrometer equipped with an array detector may further enhance the capabilities of mass spectrometry for the structural identification of biological compounds. Furthermore, some improvement in $\mathrm{S} / \mathrm{N}$ would be achieved by using a single exposure without scanning the product-ion beams across the array, but the improvement would be achieved by sacrificing mass range in the product-ion spectrum. The quality of the spectra obtained by using our technique is very similar to that obtained with microelectrospray so that, in either case, one would have difficulty sequencing a totally unknown peptide. Enough information can, however, be obtained from these data for confirmatory purposes. The quality of information obtained at these levels is also sufficient to obtain sequence tags for use in database screening. ${ }^{30,31}$ The MS/MS data reported for the nanospray ionization source showed that the peptide amino acid sequence could be determined at a comparable level. ${ }^{3}$

Other options for sensitivity enhancement include sector instruments that are interfaced to ion traps ${ }^{32}$ or to time-offlight mass spectrometers. These designs also provide a multichannel advantage. Furthermore, they are of more contemporary design, possessing smaller footprints, more automated control than is available with the ZAB-T and greater compatibility with ESI. These latter instruments will likely enjoy more support from manufacturers than the large, four-sector tandem instruments.

\section{Acknowledgments}

This research was supported in part by the NSF (Grant CHE9017250) and the NIH (Grant P41 RR00954). We are grateful to Isco Corporation for the gift of a CE unit.

\section{References}

1. A.L. Burlingame, R.K. Boyd and S.J. Gaskell, Anal. Chem. 68, 599R (1996).

2. M.R. Emmett and R.M. Caprioli, J. Am. Soc. Mass Spectrom. 5, 605 (1994).

3. M. Wilm and M. Mann, in Proceedings af the 42nd ASMS Conference on Mass Spectrometry, p. 770, Chicago, IL (1994).

4. M. Wilm and M. Mann, Anal. Chem. 68, 1 (1996).

5. F.E.P. Mikkers, F.M. Everaerts and Th.P.E.M. Verheggen, J. Chromatogr. 169, 11 (1979).

6. J.W. Jorgenson and K.B. Lukacs, J. Chromatogr. 218, 209 (1981).

7. J.W. Jorgenson and K.B. Lukacs, Anal. Chem. 53, 1298 (1981).

8. J.W. Jorgenson and K.B. Lukacs, Science 222, 266 (1983).

9. K.B. Tomer, L.J. Deterding and C.E. Parker, in High Performance Capillary Electrophoresis, Ed by M.G. Khaledi. John Wiley and Sons, Inc., New York, p. 405 (1998).

10. J.A. Olivares, N.T. Nguyen, C.R. Yonker and R.D. Smith, Anal. Chem. 59, 1230 (1987).

11. M.A. Moseley, L.J. Deterding, K.B. Tomer and J.W. Jorgenson, Rapid Commun. Mass Spectrom. 3, 87 (1989).

12. M.A. Moseley, L.J. Deterding, K.B. Tomer and J.W. Jorgenson, Anal. Chem. 63, 109 (1991).

13. M.L. Gross, in Methods in Enzymology, Ed by J.A. McCloskey. Academic Press, New York, p. 131 (1990).

14. L.J. Deterding, M.A. Moseley, K.B. Tomer and J.W. Jorgenson, Anal. Chem. 61, 2504 (1989).

15. R.M. Caprioli and K.B. Tomer, in Continuous Flow Fast Atom Bombardment Mass Spectrometry, Ed by R.M. Caprioli. Wiley \& Sons, New York, p. 93 (1990).

16. J.S.M. deWit, L.J. Deterding, M.A. Moseley, K.B. Tomer and J.W. Jorgenson, Rapid Commun. Mass Spectrom. 2, 100 (1988).

17. P. Roepstorff and J. Fohlman, Biomed. Environ. Mass Spectrom. 11, 601 (1984).

18. K. Biemann, Biomed. Environ. Mass Spectrom. 16, 99 (1988).

19. J-T. Wu, L. He, M.X. Li, S. Parus and D.M. Lubman, J. Am. Soc. Mass Spectrom. 8, 1237 (1997). 
20. D. Figeys, l. van Oostveen, A. Ducret and R. Aebersold, Anal. Chem. 68, 1822 (1996).

21. D. Figeys and R. Aebersold, Electrophoresis 19, 885 (1998).

22. R.D. Smith, H.R. Udseth, J.H. Wahl, D.R. Goodlett and S.A. Hofstadler, Methods Enzymol. 271, 448 (1996).

23. A.J. Tomlinson and S. Naylor, J. Liq. Chromatogr. 18, 3591 (1995).

24. S. Naylor, Q. Ji, K.L. Johnson, A.J. Tomlinson, W.C. Kieper and S.C. Jameson, Electrophoresis 19, 2207 (1998).

25. S. Naylor and A.J. Tomlinson, Talanta 45, 603 (1998).

26. D. Figeys, A. Ducret and R. Aebersold, J. Chromatogr. A $763,295(1997)$.
27. D. Figeys and R. Aebersold, Electrophoresis 18, 360 (1997).

28. D. Figeys, S.P. Gygi, Y. Zhang, J. Watts, M. Gu and R. Aebersold, Electrophoresis 19, 1811 (1998).

29. D. Figeys, Y. Zhang and R. Aebersold, Electrophoresis 19, 2338 (1998).

30. J.K. Eng, A.L. McCormack and J.R. Yates, Ill, J. Am. Soc: Mass Spectrom. 5, 976 (1994).

31. M. Mann and M. Wilm, Anal. Chem. 66, 4390 (1994).

32. Analytical News, Vol. XCVIl (No. 2), Summer (1997).

Received: 12 May 1998

Revised: 5 January 1999

Accepted: 11 Jamuary 1999

Web Publication: 8 April 1999 